\title{
Introduzindo as Relatividades Especial e Geral no Primeiro Ano do Ensino Médio
}

Chaleilson de Oliveira Miranda ${ }^{1}$, Michael Monteiro Matos ${ }^{2}$, Geordany Melo Correa Coelho ${ }^{3}$

\author{
1,2,3 Universidade Federal do Tocantins
}

Palavras-Chave: Relatividade, Gravitação, Ensino Médio.

\section{Introdução}

A busca pelas origens do homem e do universo vem ocupando filósofos, religiosos e cientistas a muitos séculos, no entanto durante um longo tempo essas indagações foram respondidas através dos mitos cosmológicos que atribuíam causas sobrenaturais a origem de tudo e de todos. Levaria ainda um longo tempo para que essas perguntas pudessem ser respondidas com base em observações astronômicas e rigor matemático.

Como mostrado em Porto e Porto (2010), durante um longo período o pensamento cosmológico foi fortemente influenciado pelas ideias Aristotélicas, no entanto esta era uma formulação fundamentada em princípios puramente filosóficos, carente de ferramentas matemáticas, comuns a Física dos dias atuais, apenas com o desenvolvimento da ciência moderna, a questão cosmológica começou a ser investigada a partir de um discurso racional e ainda antes da primeira metade do século XX temos o surgimento da Cosmologia cientifica inaugurada com a reinterpretação dos efeitos gravitacionais permitida pela Relatividade Geral de Einstein.

Em 1905 o chamado ano miraculoso Einstein então um jovem e desconhecido físico sem posição acadêmica de destaque publica 4 artigos originais todos de importância histórica para a ciência, dentre esses, um intitulado "Sobre a Eletrodinâmica dos Corpos em Movimento" marcaria o início da Teoria da Relatividade que viria perturbar as bases do solido castelo erguido pela mecânica Newtoniana. A Relatividade Especial ou Relatividade Restrita era uma teoria limitada aos referenciais inerciais Einstein ainda levaria dez anos para completar sua teoria com a Relatividade Geral.

Newton descreve a gravidade como uma força de atração entre massas, essa força varia diretamente como o produto das massas e com o inverso do quadrado da distância entre elas, a gravitação Newtoniana fortemente testada experimentalmente pode ser considerada uma das grandes vitorias intelectuais da humanidade e das joias do período iluminista.

A Relatividade Geral é fundamentalmente uma nova teoria da gravidade, partindo de seus famosos gedankenexperiment (experimentos mentais em alemão), Einstein estabelece o chamado Princípio da Equivalência o qual afirmar ser impossível distinguir a diferença entre um movimento acelerado e o repouso dentro de um campo gravitacional. Einstein reinterpreta o efeito gravitacional como produto da deformação sofrida pelo espaço devido a presença da massa. Novelo (2010) afirma que segundo a Relatividade Geral a aceleração produzida pela força gravitacional como um movimento em uma geometria não euclidiana, ou seja, uma geometria curva.

Apesar da gigantesca mudança na compreensão do universo proporcionada pela Relatividade Geral ela ainda é pouco conhecida do público em geral, fato que pode ser explicado pela complexidade matemática envolvida nesta teoria.

Este trabalho propõem uma apresentação da Relatividade Especial e Geral ainda no primeiro ano do ensino médio, esta apresentação teria foco nos aspectos qualitativos da teoria e seria feita após os conteúdos de Gravitação Newtoniana, com o objetivo de após apresentados os temas referentes a Relatividade Especial e Geral, seria feito um contraponto entre a teoria clássica e a moderna na descrição dos efeitos gravitacionais.

\section{Metodologia}

A metodologia empregada será uma mistura de debates onde os alunos poderão expor seu entendimento sobre determinados fenômenos e confronta-los com as previsões da relatividade que deve abrir caminho para uma exposição dialogada dos conteúdos referentes a Teoria da Relatividade e será dividida nas seguintes etapas:

Aula 1: Como Surgi-o a Teoria da Relatividade? Esta aula deve ter um foco nas implicações históricas que levaram a Teoria da Relatividade. Aula 2: O que a teoria faz? Esta aula dever focar nos limites da Física de Newton e apresentar os fenômenos que são melhor explicados pela 
Relatividade. Aula 3: O que é a gravidade para Einstein? Esta aula deve apresentar a interpretação da gravidade feita através da Relatividade Geral em confronto com a teoria clássica ao final o professor deve apresentar as provas experimentais da Relatividade Geral, abrindo caminho para discutir de um ponto de vista qualitativo a confirmação das ondas gravitacionais. Ao final do terceiro momento os alunos serão estimulados a produzir um texto onde eles devem expor as ideias que mais os chamaram a atenção bem como explicar as diferenças percebidas entre a mecânica de Newton e a relatividade de Einstein.

\section{Conclusões}

Apesar de seu caráter revolucionário e as inúmeras mudanças na compreensão tanto das origens como da evolução do universo alcançada com a Teoria da Relatividade, está ainda parece confinada ao ambiente acadêmico, onde só os iniciados em Física avançada são capazes de apreciar a beleza envolvida nessa formulação da natureza. Esperamos que o trabalho permita ao estudante do ensino médio compreender os aspectos essenciais dessa teoria bem como as implicações culturais proporcionadas por ela.

\section{Referências}

NOVELO, M. O que é Cosmologia? Rio de Janeiro: Editora Jorge Zahar, 2010.

PORTO; C. M; PORTO; M. B. D. S. M. A Evolução do Pensamento Cosmológico e o Nascimento da Ciência Moderna. Revista Brasileira de Ensino de Física, v. 30, n. 4, 2008. 